\title{
¿Cuáles son los riesgos de dispersión del COVID-19 en México?
}

\author{
What are the risks of COVID-19 \\ dispersion in Mexico? \\ José Carlos Peña Rodríguez*
}

Citar como: Peña RJC. ¿Cuáles son los riesgos de dispersión del COVID-19 en México? Acta Med. 2021; 19 (1): 151-156. https://dx.doi.org/10.35366/98594

\section{Resumen}

En este pequeño ensayo la idea es presentar las vías más frecuentes de dispersión del COVID-19 y el número de virus (partículas) que eliminan los sujetos asintomáticos, presintomáticos y sintomáticos durante la conversación, la tos, el estornudo y el simple respirar. Con 1,000 partículas del virus es suficiente para infectarse. Por ejemplo, un acceso de tos o un estornudo puede expulsar hasta 200 millones de partículas virales. Por lo que en lugares cerrados la posibilidad de infección se eleva exponencialmente: el hogar, la oficina, las iglesias, los centros comunitarios, los mercados y los restaurantes. En el exterior la presencia de aerosoles con COVID-19 obliga al uso de cubrebocas, lo cual ha demostrado su eficacia. El aumento en la movilidad en todos los lugares del mundo se ha acompañado siempre de repuntes de la dispersión de la enfermedad. Por lo que es crítico evitar al máximo la apertura de actividades antes de tener una caída significativa en el número de contagios y de muertes comunitarias.

Palabras clave: COVID-19, dispersión, gotas de Flügge, contagio, el hogar, lugares cerrados, medio ambiente.

\section{INTRODUCCIÓN}

Ésta es una reflexión sobre los riesgos de contraer y dispersar el COVID-19 en particular y al reanudar actividades, conózcalos y prevéngalos.

\footnotetext{
* Director Médico. Centro de Diagnóstico Ángeles. Ciudad de México, México.
}

Correspondencia:

Dr. José Carlos Peña Rodríguez

Correo electrónico: josecarlos.pena@saludangeles.com

Aceptado: 02-12-2020.

www.medigraphic.com/actamedica

\section{Abstract}

In this essay, we present factors that favors the dispersion of the virus COVID-19 in the community and the risks for the mobility specially in the big cities. We analyzed the number of viral particles expelled by subjects: contaminated, asymptomatic, pre-symptomatic and symptomatic during conversation, sneeze, cough and normal breathing. Inhale 1,000 particles of the virus is sufficient to get an infection. With just a cough or a sneeze, a person infected can expel more than 200 million particles to the environment. If that happens in a closed facility (home, room, office), the possibility of infection rises exponentially. The use of a mask is highly recommended in all situations. The opening to activities in many cities, was followed by a rebound in the dispersion of the virus. It is advisable to avoid a premature opening, before a significant and sustained decrease occurred in the number of cases and deaths in the community.

Keywords: COVID-19, dispersion, Flügge droplets, contagion, household, indoor, environment.

La población en México, mal informada, ha ignorado por razones que desconozco, las medidas establecidas por la Secretaría de Salud y está convencida de que la pandemia ha reducido su peligrosidad. Yo no creo que esto esté ocurriendo. Las curvas epidémicas son relativamente predecibles con un periodo progresivo de ascenso, un pico máximo con o sin meseta y una caída más lenta que la curva de ascenso. Tenemos datos robustos de las epidemias de China, Italia, Alemania y Francia que informan ${ }^{1}$ que el descenso de la mortalidad fue más lenta, pero con decesos que persisten por meses. En México nuestras curvas siguen al alza en casos sospechosos, comprobados y en mortalidad; de hecho, en el mes de noviembre el número de casos alcanzó el pico máximo de contagios durante los últimos 10 meses (informe de la Secretaría de Salud del 25 
de noviembre 10,335 con 858 fallecimientos). ${ }^{2}$ La apertura que se ha iniciado en la Unión Americana, ${ }^{3}$ por los resultados obtenidos hasta ahora, no sólo fue prematura, sino sumamente peligrosa, y los contagios y muertes los van alcanzar quieran o no. México está en una etapa más temprana que los Estados Unidos y con una apertura, como la actual, nos puede ir peor. El mejor criterio es el emitido por las autoridades sanitarias. "Una reducción sostenida y demostrada en el número de contagios, hospitalizaciones y decesos, durante al menos dos semanas continuas (el ciclo típico del SARS-CoV-2 en el organismo humano). Esta verificación de la reducción sostenida es la base principal para poder imaginar el fin del aislamiento social."1

\section{¿En qué lugares se enferma la gente?}

La mayoría de las personas se contagian en su propio hogar. La razón es simple, si un miembro de ese núcleo familiar se contagia, su presencia y el contacto constante con los miembros de su misma casa, trae como consecuencia el contagio.

En los siguientes párrafos se explicará de qué manera nos exponemos a los virus y qué medidas prácticas debemos tomar para evitar infectarnos o infectar a los demás.

Para contagiarse debe haber una exposición a una cantidad suficiente del virus. Basados en las infecciones por otros coronavirus y virus de la influenza que han sido estudiados a lo largo de las últimas décadas, parece ser que pequeñas cantidades del virus pueden ser contaminantes. Algunos expertos consideran que con sólo exponerse a 1,000 partículas del SARS-CoV-2 es suficiente para contagiarse. Para fines prácticos podemos tomar esa cifra como el número mágico para explicar cómo puede ocurrir el contagio del virus al que usted puede exponerse al recibir estas partículas en una respiración o al frotarse los ojos con las manos contaminadas: si usted se expone a 100 partículas cada vez que inspira (la gente efectúa de 15-20 respiraciones/min en promedio), en 10 inspiraciones inhalaría 1,000 partículas del virus e igualmente ocurriría con 10 frotamientos de ojos. Cada una de estas situaciones nos pone en riesgo de adquirir una infección. Por eso, el uso de cubrebocas, el lavado frecuente de manos y el evitar frotarse los ojos son medidas efectivas para evitar el contagio.

\section{¿Cuántos virus se liberan e inciden en el medio ambiente?}

En un baño. Los baños compartidos representan un gran peligro de infección. En la tina, en las regaderas, en el lavabo, en las puertas, en las paredes. Si el virus se excreta por heces, como es probable, no sabemos si al vaciar el inodoro se liberen partículas del virus que se peguen a las paredes de éste. Sobre todo en los baños públicos. Los baños deben ser sanitizados con relación a su uso.
La tos. Un solo tosido libera al ambiente 3,000 minigotas (gotas de Flügge) con virus que viajan a $80 \mathrm{~km} /$ hora. La mayoría de estas gotas son grandes y caen rápidamente al suelo por efecto de la gravedad, pero las más pequeñas quedan en el aire y viajan rápidamente a través de una habitación.

El estornudo. Un estornudo libera 30,000 gotas de Flügge que viajan a $300 \mathrm{~km} /$ hora. La mayoría de las gotas son pequeñas y se trasladan a grandes distancias (fácilmente a través de un cuarto, de un vagón del metro, un camión de pasajeros o un espacio para triaje). Si una persona está infectada puede expulsar en un estornudo 200 millones de partículas virales que se dispersan en el ambiente que rodea a la persona infectada (Figura 1).

La respiración. Una sola respiración por la boca libera de 50-5,000 gotitas de Flügge. La mayoría de estas gotas viajan poco y caen al suelo rápidamente, a la mesa o a muebles cercanos. Si se respira por la nariz, la cantidad de gotas liberadas es mucho menor. Es muy importante señalar que la exhalación tiene poca fuerza, por lo que las partículas virales de las vías respiratorias bajas (tráquea y bronquios) no se expelen fácilmente.

En contra de lo que ocurre con el estornudo o la tos, la respiración normal expulsa pequeñas cantidades de virus. No conocemos los datos para el COVID-19, pero tenemos el virus de la influenza como referencia: por estudios con este virus se sabe que libera 33 partículas por minuto. Para facilitar los cálculos que vamos hacer más adelante usaremos 20 partículas por minuto.

Si una persona contagiada tose o estornuda, envía 200 millones de partículas de virus que se diseminan ampliamente. Algunos virus pueden quedar en el aire, la mayoría caen al suelo, pero otros se depositan en las superficies que los rodean: puertas, paredes, pasamanos, mesas, escritorios, etcétera. Al estar cara a cara, conversando, interrogando o explorando a una persona infectada y estornuda o tose, es muy fácil entender que se inhala mucho más de 1,000 partículas, cantidades suficientes para infectarse. $\mathrm{Ni}$ con la sana distancia estamos a salvo, pero el uso de cubrebocas y el lavado de manos nos protege. Si la distancia es corta, la persona infectada tiene que utilizar un cubrebocas adsorbente que impida la diseminación del virus. Aun si la tos o el estornudo no va dirigido directamente a usted, algunas de las gotitas más pequeñas persisten en el aire, contaminan cada esquina o espacio de un cuarto pequeño. Por lo que si en los siguientes minutos usted permanece o alguien entra al cuarto y aspira el aire, recibirá suficientes virus para infectarse.

Con una respiración normal un sujeto infectado elimina 20 partículas/minuto y en el supuesto caso de que usted inhalara esas 20 partículas/minuto necesitaría 50 minutos para alcanzar las 1,000 partículas para contagiarse. 
Conversar. El hablar libera 200 gotas o virus/minuto. Es decir, una conversación cara a cara por cinco minutos bastaría para obtener una dosis suficiente de 1,000 partículas para contaminarse. ${ }^{4}$

De acuerdo con la fórmula exposición al virus X tiempo, cualquier conversación cara a cara por 10 minutos o más sería suficiente para contaminarse $(10 \mathrm{~min} \times 20$ partículas/minuto $=2,000$ partículas). En la oficina, en el consultorio, una conversación o consulta no protegida sería un alto riesgo de contaminación. El mejor consejo es quedarse en su casa donde la posibilidad de contagiar a otros o contagiarse usted es menos probable.

\section{¿Cuál es el papel de los portadores asintomáticos para dispersar la infección? $?^{5,6}$}

Los pacientes sintomáticos no son los únicos capaces de contagiar. Sabemos que más o menos $44 \%$ de todas las infecciones o de las transmisiones que ocurren en una comunidad son por personas sin síntomas (asintomáticos o presintomáticos). Una persona presintomática puede dispersar la infección dentro de los cinco días previos a la aparición de los síntomas.

Se ha informado que el talón de Aquiles del contagio por COVID-19 reside en los enfermos asintomáticos. ${ }^{6}$

La población infectada ocurre en todos los rangos de edad y con diferente cantidad de carga viral. La cantidad de virus liberados por pacientes infectados cambia en relación con la evolución de la infección y difiere de persona a persona. La carga viral aumenta hasta el momento en que aparecen los síntomas. De manera que antes de que se presenten los síntomas la persona está liberando virus al medio ambiente. ${ }^{6}$

La cantidad de virus liberados por una persona infectada cambia durante el curso de la infección y también es diferente de persona a persona. La carga viral aumenta progresivamente hasta que la persona se vuelve sintomática. Es interesante que sólo $20 \%$ de los infectados sean
Las personas infectadas asintomáticas pueden emitir aerosoles con partículas infecciosas al respirar o hablar. La falta de uso del cubrebocas maximiza la exposición, en tanto que el uso generalizado da como resultado la exposición mínima.

Tamaño de las partículas $(\mu \mathrm{m})$
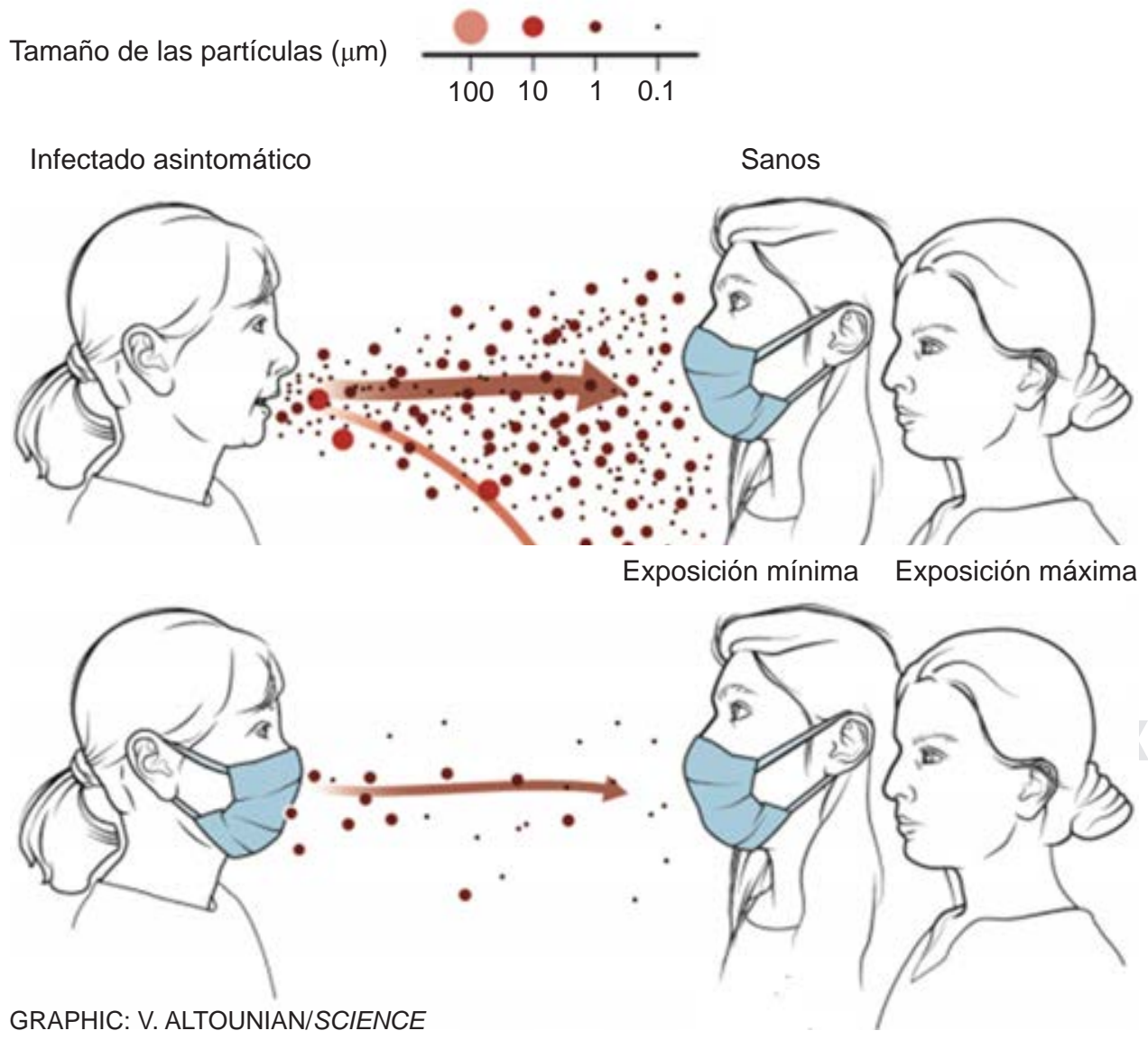

Figura 1:

Los cubrebocas reducen la transmisión aérea del virus. Modificado de: Prather KA, Wang CC, Schooley RT. Reducing transmission of SARS-CoV-2. Science. 2020; 368 (6498): 1422-1424. doi: 10.1126/science.abc6197. 
los responsables de 99\% de la carga viral que puede potencialmente ser liberada al medio ambiente.

Vamos ahora al meollo del asunto. ¿Dónde residen los problemas de la dispersión del virus? ${ }^{5}$

Después de los hogares, los sitios con más posibilidad de contagio son:

- Bodas, funerales, cumpleaños: $10 \%$ del contagio.

- Lugares de trabajo: específicamente negocios, cara con cara es también de $10 \%$ o más de acuerdo con los espacios en que se lleven a cabo las conversaciones. Piensen en las unidades de diálisis y salas de espera.

- Negocios o consultorios con entrevistas cara a cara o en un lugar de trabajo compartido por muchos. Una persona infectada que pasa ocho horas en su trabajo puede contaminar a las personas cercanas.

Con la movilidad que se abrió en estas últimas semanas, si asistimos a un restaurante, una taquería, una cantina, ¿qué puede pasar en esos ambientes si son cerrados? La capacidad de contaminación de una persona enferma es muy grande, ya que un estornudo o un acceso de tos pueden diseminar millones de virus a grandes distancias (10 y 20 m), como ya se explicó. En lugares con ventilación y aire acondicionado el flujo de aire en general circula de donde se inyecta, derecha a izquierda o viceversa, todos los comensales que reciben ese flujo de aire de un comensal infectado reciben cantidades variables de virus. Pero aun una persona contagiada que sólo elimina virus por la respiración normal en un espacio cerrado por un tiempo de una hora o más es suficiente para contaminar el ambiente y propagar la enfermedad.

\section{Mercados y supermercados}

Mercados mexicanos como la Viga, la Merced, Central de Abastos y todos con estas características, pueden tener diversos grados de contagio. En la Merced hubo una gran cantidad de contagios en el mes de mayo entre los dueños de puestos, uno de ellos, que es mi paciente, estuvo intubado por ocho días y sobrevivió, perdió durante su enfermedad $12 \mathrm{~kg}$. Me comentó que de sus compañeros y vecinos de puestos, muchos se contagiaron y fallecieron. A pesar de lo espacioso de estos mercados, la densidad de gente y lo cercano de los diversos puestos de la mercancía favorecen el contacto.

Los supermercados son menos peligrosos, es más fácil el distanciamiento, son más amplios y bien ventilados; dejan entrar menos gente y bajan la densidad. El cliente directamente obtiene los productos, verduras, latería, bebidas, cárnicos, aves, embutidos previamente empacados. Es poco el contacto del usuario con las personas que ofrecen los servicios. Lo que defiende al consumidor en estos lugares es la estancia corta de menos de una hora, pero en los trabajadores que están más de ocho horas el riesgo aumenta.

\section{Cumpleaños y funerales}

La transmisión del virus que se contagia en el hogar y se disemina en la comunidad a través de cumpleaños, funerales y asistencia a las iglesias se cree que ha sido el mecanismo más importante de la transmisión de COVID-19 en todas las ciudades del mundo.

\section{Lugares de trabajo}

Oficinas. ¿Cuánta gente se contagia en un lugar de trabajo? De hecho, no se sabe. Un espacio cerrado con un solo paciente infectado es capaz de contaminar decenas de personas. Piensen ustedes en nuestras salas de hemodiálisis en CEDIASA; sin embargo, en nuestras unidades la contaminación ha sido baja gracias a la gran cantidad de medidas que hemos tomado para evitar el contagio, aun cuando de manera reciente ha vuelto a repuntar posiblemente por la apertura permitida por las autoridades y la gran susceptibilidad de nuestra población.

Como pueden ver, todos estos brotes ocurrieron en lugares cerrados, con mucha conversación, cantos, gritos y ausencia de sana distancia.

\section{Calidad del aire e infección por COVID-19 y el uso de cubrebocas ${ }^{8,9}$}

Recientemente el Dr. Mario Molina, nuestro Premio Nobel, con un grupo de expertos en contaminación, refirió que en las ciudades en las que abundan partículas de 2.5 micrómetros tienen la capacidad de fijar virus como COVID-19 y mantenerlos en la atmósfera por periodos largos de tiempo, ya que por su tamaño y ligereza persisten en el aire. ${ }^{9}$ En un estudio en ciudades con diversos grados de contaminación por estas pequeñas partículas los pobladores presentaron más enfermedades pulmonares y renales. Si a ello se suma que estas partículas sean portadoras de COVID-19, las hace aún más peligrosas; por lo que el empleo del cubrebocas debe ser obligatorio, ya que evita la entrada de estos aerosoles a las vías respiratorias. No necesariamente la sana distancia y el quedarse en casa son suficientes para evitar la contaminación entre personas, puesto que el aerosol del aire constituido por esas partículas flotantes es altamente contaminante. Esto hace que el uso del cubrebocas sea imperativo. Esta sola medida protectora, entre el 6 de abril y el 9 de mayo, redujo de manera significativa el número 
de infecciones, 78,000 casos en Italia y 66,000 casos en la Ciudad de Nueva York, epicentros de la epidemia en ese momento. ${ }^{9}$

La contaminación ambiental con aerosoles constituidos por partículas de 2.5 micrómeros, al fijar virus, mantienen a éstos en la atmósfera por tiempos prolongados, lo cual hace obligatorio el uso del cubrebocas al salir a la calle.

\section{DISCUSIÓN}

A medida que aumente la movilidad, hay posibilidades de contagiarnos y contagiar a nuestras familias y compañeros de trabajo. O sea, reanudar el trabajo cuando tengamos la oportunidad, en el caso de México, yo todavía lo veo un tanto lejano.

Lo que pretende este pequeño ensayo es hacer hincapié en los factores de riesgo de la dispersión del virus en la comunidad. Las comunidades descuidadas o poco receptivas a las medidas de seguridad y que hacen caso omiso de los factores de riesgo, que ya se mencionaron, están en más peligro de contraer la infección y de transmitirla como ha ocurrido y ocurre en México en los últimos nueve meses. Es un hecho que nos hemos enfocado a la contaminación respiratoria que es sin duda la más común, aun cuando otras vías como son las mucosas de los ojos y la boca también contribuyen. El vehículo de transmisión son las manos contaminadas en superficies de todo tipo y después llevárselas a los ojos y a la boca. Por eso hay que evitar los saludos de mano, su lavado permanente y hasta el empleo de guantes.

Al aumentar la movilidad, como está ocurriendo, a pesar de tomar todas las medidas pertinentes, los contagios pueden aumentar sustancialmente e incrementar los riesgos de internamiento, la aparición de numerosas complicaciones propias de la enfermedad y muertes derivadas de éstas. Si a ello se le suman comorbilidades como la edad, la diabetes, la obesidad, la hipertensión arterial y otras enfermedades crónico-degenerativas, el peligro de secuelas clínicas y de muerte aumenta. ${ }^{10,11}$

Un punto que tratamos con detalle es el de los portadores asintomáticos o presintomáticos que son, de acuerdo con un artículo del New England Journal of Medicine (NEJM), ${ }^{6}$ el talón de Aquiles para controlar la dispersión del virus.

Los aerosoles en el ambiente donde pululan partículas de 2.5 micrómeros colonizadas con el coronavirus hacen obligatorio el uso del cubrebocas como lo enfatiza con su información el Dr. Molina y colaboradores. ${ }^{9}$

La vacuna está casi a nuestro alcance, pero hay que esperar todavía unos meses $y$, aun contando con ella, se deben desarrollar de manera eficiente programas de vacunación que alcancen a millones de personas; un gran reto para las autoridades de salud. A esto hay que sumar la voluntad de la población de someterse a este procedimiento y de asistir a los lugares que indiquen las autoridades. Mientras tanto, debemos conservar las medidas de prevención ya mencionadas. Muchas de ellas llegaron para quedarse, como es el uso del cubrebocas.

\section{CONCLUSIONES}

Nunca moverse o asistir a eventos sin llevar cubrebocas además de lentes, careta y guantes. Mantener la sana distancia.

Evitar al máximo asistir a lugares cerrados.

El talón de Aquiles del contagio reside en los pacientes asintomáticos o presintomáticos.

Cuidarse dentro del hogar, sobre todo si hay familiares que salen a la calle a realizar diversas labores.

Los aerosoles en el medio ambiente son altamente contaminantes y contribuyen a la dispersión del virus.

Aun cuando nos hemos enfocado más al contagio respiratorio, el contacto a través de las manos puede ser igual de riesgoso. Por eso lavarse las manos frecuentemente es otra medida para evitar el contagio. De este modo nos ayudaremos a nosotros y a otros.

El documento de los ex secretarios de salud ofrece una información puntual y completa, que abarca no sólo los datos de México, sino de todos los países del mundo. Por último, estoy de acuerdo con la aseveración final de este documento:

"Seguimos en un pasaje de incertidumbre, dolor y miedo. Lo más probable es que esta circunstancia se prolongue. Son tiempos oscuros, a los que sólo podremos gestionar con la razón."1

\section{REFERENCIAS}

1. Chertorivsky S, Córdova JA, Frenk J, Juan M, Narro J, Soberón G. La gestión de la pandemia en México. Análisis preliminar y recomendaciones. México: Consejo Consultivo Ciudadano Pensando en México; 2020. pp. 11-131.

2. Grupo Reforma Especial COVID-19 en México. Actualizado al 25/11/2020. Publicado en su página electrónica del 26 de noviembre 2020.

3. Wilkinson-Ryan T. Our minds aren't equipped for this kind of reopening. The Atlantic. 6 de julio de 2020.

4. Morawska L, Milton DK. It is time to address airborne transmission of coronavirus disease 2019 (COVID-19). Clin Infect Dis. 2020; 71 (9): 2311-2313.

5 Salas J, Mariano Z. Radiografía de tres brotes: así se contagiaron y así podemos evitarlo. El País. 8 de junio de 2020. Disponible en: https://elpais.com/ciencia/2020-06-06/radiografia-de-tres-brotes-asise-contagiaron-y-asi-podemos-evitarlo.html

6. Gandhi M, Yokoe DS, Havlir DV. Asymptomatic transmission, the Achilles' heel of current strategies to control COVID-19. N Engl J Med. 2020; 382 (22): 2158-2160.

7. DOF: 23/03/2020, ACUERDO por el que el Consejo de Salubridad General reconoce la epidemia de enfermedad por el virus SARS- 
CoV-2 (COVID-19) en México, como una enfermedad grave de atención prioritaria, así como se establecen las actividades de preparación y respuesta ante dicha epidemia. Disponible en: http://dof.gob.mx/notaDetalle.phpcodigo $=5590161 \& \mathrm{fec}$ ha $=23 / 03 / 2020$

8. Maclntyre CR, Chughtai AA. A rapid systematic review of the efficacy of face masks and respirators against coronaviruses and other respiratory transmissible viruses for the community, healthcare workers and sick patients. Int J Nurs Stud. 2020; 108: 103629. Available in: https://www.ncbi.nlm.nih.gov/pmc/articles/ PMC7191274/
9. Zhanga R, Li Y, Zhang AL, Wang Y, Molina MJ. Identificando la transmisión aérea como la ruta dominante para la propagación del COVID-19. Science of the Total Environment. 2020. Disponible en: https://centromariomolina.org/wp-content/uploads/2020/06/ Espa\%C3\%B1ol_3o-COVID-Zhang-MM_fin.pdf

10. Zhu J, Ji P, Pang J, Zhong Z, Li H, He C et al. Clinical characteristics of 3062 COVID-19 patients: a meta-analysis. J Med Virol. 2020; 92 (10): 1902-1914. doi: 10.1002/jmv.25884.

11. Guan WJ, Ni ZY, Hu Y, Liang WH, Ou CQ, He JX et al. Clinical characteristics of coronavirus disease 2019 in China. N Engl J Med. 2020; 382 (18): 1708-1720. 